\title{
TCR-triggered extracellular superoxide production is not required for T-cell activation
}

\author{
Aleksey V Belikov ${ }^{1 *}$, Burkhart Schraven ${ }^{1,2}$ and Luca Simeoni ${ }^{1}$
}

\begin{abstract}
Background: In the last decade, reactive oxygen species (ROS) production has been shown to occur upon T-cell receptor (TCR) stimulation and to affect TCR-mediated signalling. However, the exact reactive species that are produced, how ROS are generated and their requirement for T-cell activation, proliferation or cytokine production remain unclear, especially in the case of primary human T cells. Moreover, several groups have questioned that ROS are produced upon TCR stimulation.

Results: To shed some light onto this issue, we specifically measured superoxide production upon TCR ligation in primary human and mouse T lymphocytes. We showed that superoxide is indeed produced and released into the extracellular space. Antioxidants, such as superoxide dismutase and ascorbate, abolished superoxide production, but surprisingly did not affect activation, proliferation and cytokine secretion in TCR-stimulated primary human T cells. It has been suggested that T cells produce ROS via the NADPH oxidase 2 (NOX2). Therefore, we investigated whether T-cell activation is affected in NOX2-deficient mice $\left(g p 9 p^{\text {phox }{ }^{-1}-}\right.$ ). We found that T cells from these mice completely lack inducible superoxide production but display normal upregulation of activation markers and proliferation.

Conclusions: Collectively, our data indicate that primary T cells produce extracellular superoxide upon TCR triggering, potentially via NOX2 at the plasma membrane. However, superoxide is not required for T-cell activation, proliferation and cytokine production.
\end{abstract}

Keywords: Reactive oxygen species, ROS, T lymphocyte, T-cell receptor, Proliferation, Cytokine profile, NADPH oxidase, NOX2, gp $91^{\text {phox- }- \text { - }}$, Antioxidants

\section{Background}

$\mathrm{T}$ cells play a central role in immune responses and are also involved in the pathogenesis of many diseases. Therefore, a better understanding of the molecular mechanisms regulating T-cell activation is crucial for the development of modern therapeutic tools. In the last decade, it has been shown that TCR triggering leads to the generation of ROS in preactivated T cells, e.g. human and mouse T-cell blasts and Jurkats, resulting in activation-induced cell death (AICD) [1-7]. More recently, redox changes upon TCR stimulation were detected in the mitochondria of primary mouse T cells [8]. However, ROS production upon triggering of the TCR in primary human $\mathrm{T}$ cells still remains unstudied. Moreover, a number of

\footnotetext{
* Correspondence: belikov.research@gmail.com

'Institute of Molecular and Clinical Immunology, Medical Faculty,

Otto-von-Guericke University, Leipziger Str. 44, 39120 Magdeburg, Germany

Full list of author information is available at the end of the article
}

studies claim that ROS are not produced upon TCR triggering in T cells [9-12].

ROS have been proposed to play a role as second messengers [13], by reversibly oxidizing cysteines in phosphatases [14], transcription factors [15], ion channels [16], adaptor molecules [17] and cytoskeleton components [18]. ROS can be inducibly produced by NADPH oxidases [19,20]. Interestingly, NOX2 [3] and DUOX1 [6] oxidases have been shown to be expressed in T cells.

An indirect evidence that ROS might be important for T-cell functions comes from studies in which various antioxidants were used. Antioxidants were shown to inhibit T-cell proliferation and IL-2 production [11,21]. However, investigation of the effect of antioxidants on TCRmediated signalling has given somewhat opposite results. Indeed, antioxidants induced sustained MEK and ERK phosphorylation and promoted mobility shift of Lck upon TCR stimulation in human T-cell blasts and Jurkats [2]. Also, depletion of intracellular glutathione 
with buthionine sulphoximine led to abrogation of antiCD3 induced $\mathrm{Ca}^{2+}$ flux in Jurkat cells [22] and inhibition of proliferation in primary human T cells [23]. Moreover, it is believed that a reducing milieu, which is promoted by antigen-presenting cells [24], is necessary for T-cell proliferation.

Thus, it is not clear whether ROS is produced and which role oxidation plays in T lymphocytes upon TCR stimulation. In particular, TCR-induced ROS production and its importance in primary human $\mathrm{T}$ cells have not been investigated. Therefore, we decided to study ROS production upon $\mathrm{CD} 3 \times \mathrm{CD} 28$ stimulation in primary human and mouse $\mathrm{T}$ lymphocytes. Additionally, we have characterized primary $\mathrm{T}$ cells from NOX2-deficient mice to assess whether inducible ROS play any role in T-cell activation. Finally, we investigated the effects of the antioxidant enzymes superoxide dismutase and catalase and the physiological antioxidant molecule ascorbate (Vitamin C) on activation, proliferation and cytokine profile of primary human T cells.

\section{Results}

TCR stimulation induces the release of extracellular superoxide in primary human $\mathrm{T}$ cells

Whether primary human T cells inducibly produce ROS upon TCR ligation has not yet been addressed. Moreover, the exact radical species which are produced and their sources in $\mathrm{T}$ cells are not well understood. Therefore, we decided to investigate these issues. We isolated peripheral blood T cells from healthy volunteers. Subsequently, cells were stimulated with CD3 and CD28 mAbs immobilized on microbeads to mimic physiological stimulation [25]. Almost all ROS in biological systems originate from superoxide; therefore, we were interested in the detection of this radical. To this aim, we utilized luminol-based superoxide detection assay Diogenes (from National Diagnostics).

We indeed detected an increase in luminol oxidation, corresponding to superoxide production, upon $\mathrm{CD} 3 \times \mathrm{CD} 28$ stimulation as compared to isotype control (Figure 1A). The peak (about 35\% increase) in T-cell specific superoxide production occurred $10 \mathrm{~min}$ after TCR-triggering and ROS levels decreased gradually afterwards. The superoxide-neutralizing enzyme superoxide dismutase (SOD), but not the hydrogen peroxide-neutralizing enzyme catalase, prevented luminol oxidation, indicating that the detected reactive oxygen specie was indeed superoxide (Figure 1B). These results also suggest that superoxide was released into the extracellular space, as SOD is membrane-impermeable. Interestingly, we were not able to detect extracellular superoxide production upon CD3 $\times$ CD28 stimulation in human T-cell blasts and Jurkat $\mathrm{T}$ cells (data not shown). In summary, primary human $\mathrm{T}$ cells produce superoxide upon TCR stimulation and release it to the extracellular space.

\section{TCR-triggered superoxide production is mediated by NADPH oxidase 2}

We showed that $\mathrm{T}$ cells produce superoxide upon TCR stimulation. One of the most well-described sources of superoxide is the phagocytic NADPH oxidase 2 (NOX2). Remarkably, NOX2 has been shown to be expressed in $\mathrm{T}$ cells [3]. We decided to analyze $\mathrm{T}$ cells from NOX2deficient mice $\left(g p 91^{\text {phox-/-}}\right)$ to investigate whether NOX2 is indeed the source of the superoxide that we detected in our system. Splenic T cells from wild type (WT) mice initiated a similar wave of superoxide production upon $\mathrm{CD} 3 \times \mathrm{CD} 28$ microbeads stimulation as human T cells, albeit with faster kinetics (Figure 2). Contrary to WT mice, T cells from $g p 91^{\text {phox-/- }}$ mice showed no inducible superoxide production upon stimulation

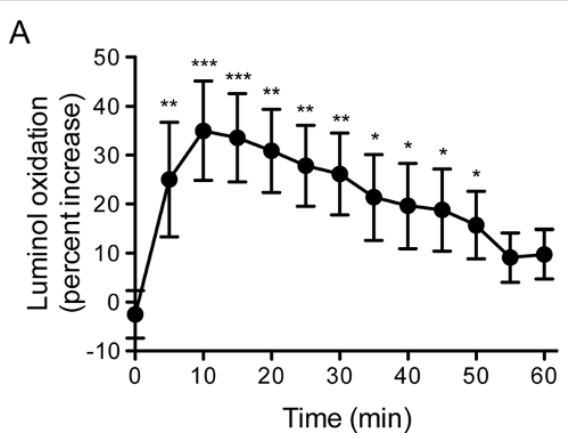

\section{B}

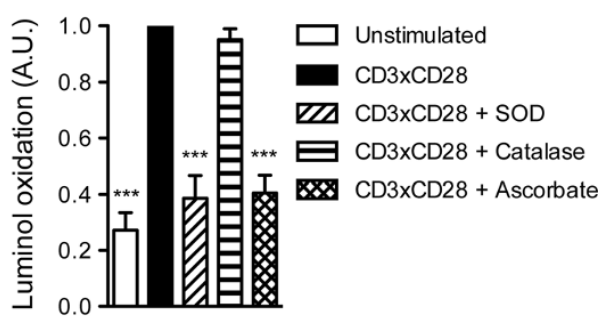

Figure 1 TCR stimulation induces extracellular superoxide release in primary human T cells. (A) Primary human T cells were stimulated with CD3xCD28- or isotype-coated microbeads. Superoxide production was measured with Diogenes assay at 5 min intervals. The values indicate the increase in luminescence in CD3xCD28- relative to isotype-stimulated samples. The data show the mean from 16 independent experiments. (B) Primary human T cells were stimulated for 10 min with CD3xCD28-coated microbeads alone or in the presence of either SOD, catalase or ascorbate. Superoxide production was measured with Diogenes assay. The values indicate the luminescence signal normalized to stimulated controls. The data show the mean from at least 4 independent experiments. 


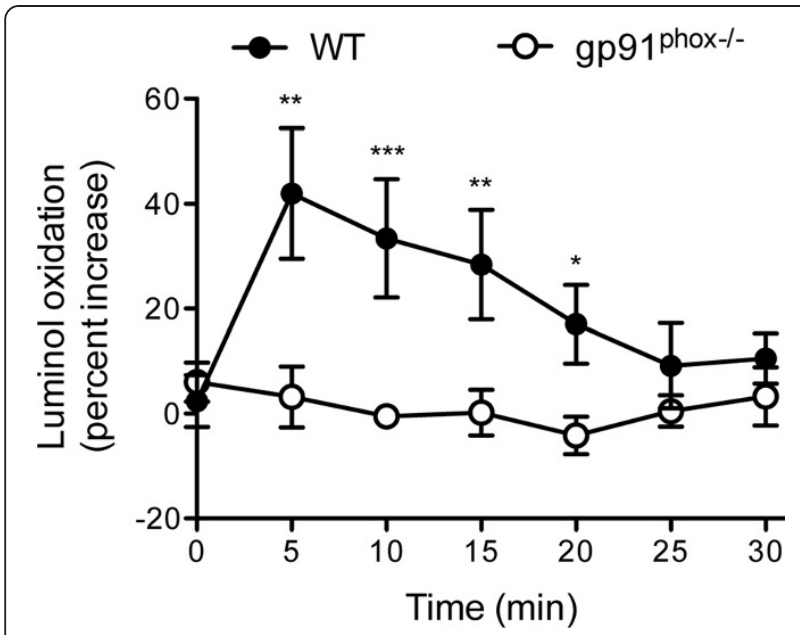

Figure $\mathbf{2}$ TCR-triggered superoxide production is mediated by NOX2 in primary T cells. Splenic T cells from either WT or $g p 91^{\text {phox- }-}$ mice were stimulated with CD3xCD28- or isotype-coated microbeads. Superoxide production was measured with Diogenes assay at 5 min intervals. The values indicate the increase in luminescence in CD3xCD28relative to isotype-stimulated samples. The data show the mean from 3 independent experiments. $2 \mathrm{WT}$ and 4 gp $91^{\text {phox- } /-}$ mice were used in each experiment.

(Figure 2). Therefore, these data confirm that NOX2 is indeed activated upon TCR triggering in primary T cells and is responsible for the rapid generation of superoxide.

\section{Inducible superoxide production is not required for primary human T-cell activation, proliferation and cytokine production}

As shown above, both human and mouse primary T cells produce superoxide upon engagement of the T-cell receptor, and this superoxide is released to the extracellular space. In order to investigate the function of superoxide in $\mathrm{T}$ cells, we neutralized it by the addition of SOD or the radical-scavenger ascorbate (Figure 1B). Subsequently, we have investigated T-cell activation, proliferation and cytokine production. As superoxide can naturally dismutate to hydrogen peroxide $\left(\mathrm{H}_{2} \mathrm{O}_{2}\right)$, we have also included samples treated with catalase in our functional assays. SOD, ascorbate and catalase are essential parts of cell-intrinsic antioxidant defense system, and therefore can be safely used without inducing off-target effects.

Initially, we stimulated primary human $\mathrm{T}$ cells with CD $3 \times$ CD28-coated microbeads for 16 hours in the presence of antioxidants and assessed T-cell activation (Figure 3A). To our surprise, the addition of SOD, ascorbate or catalase had no major effect neither on the expression of CD25 and CD69 activation markers (Figure 3B), nor on the percentage of activated $\mathrm{CD} 25^{+} \mathrm{CD} 69^{+}$cells (Figure 3C).

Next, we investigated proliferation of CD3 $\times$ CD28 stimulated human $\mathrm{T}$ cells in the presence of SOD, ascorbate and catalase using the CFSE dilution assay (Figure 4A). Consistent with the results presented above, we observed normal percentage of proliferating cells 3 days after stimulation in the presence of antioxidants (Figure 4B).

We then investigated if TCR-triggered superoxide production is involved in the regulation of $\mathrm{CD}^{+} \mathrm{T}$-cell differentiation. Therefore, we stimulated human naïve $\mathrm{CD}^{+}{ }^{+} \mathrm{T}$ cells with CD3 $\times$ CD28-coated microbeads in the presence of antioxidants and measured the concentrations of various cytokines in the supernatants after 48 hours using the Bio-Plex system (from Bio-Rad). No significant differences were observed between samples when data were normalized to stimulated controls (Figure 5), as well as when absolute concentrations were used (Additional file 1: Figure S1).

Overall, these data demonstrate that in primary human $\mathrm{T}$ cells superoxide production triggered by TCR is dispensable for activation, proliferation and cytokine production.

\section{NOX2 is not required for T-cell activation and proliferation}

As shown in Figure 2, gp $91^{\text {phox-/- }}$ mice completely lack TCR-triggered superoxide production. To assess the importance of this reactive oxygen specie in T-cell function, we have investigated the activation and proliferation of gp $91^{\text {phox-l- }} \mathrm{T}$ cells upon $\mathrm{CD} 3 \times \mathrm{CD} 28$ stimulation. In line with our observations on human T cells treated with antioxidants, upregulation of activation markers CD69 and CD25 (Figure 6A, B), percentage of $\mathrm{CD}^{2} 9^{+} \mathrm{CD} 25^{+}$cells (Figure 6A, C) and proliferation (Figure 7) were not affected in T cells from $g p 91^{\text {phox-/- }}$ mice. Altogether, these data show that NOX2 and TCR-triggered superoxide production are dispensable for primary T-cell activation and proliferation.

\section{Discussion}

In this study we showed that primary human and mouse $T$ cells produce extracellular superoxide upon triggering of the T-cell receptor. However, it appears that this reactive oxygen specie is not required for T-cell activation, proliferation and cytokine production. To our knowledge, this is the first study investigating TCR-induced superoxide production and its functional requirement in primary human $\mathrm{T}$ cells.

During the last decade, it has been extensively shown that TCR triggering leads to the generation of ROS. However, these studies were performed in preactivated $\mathrm{T}$ cells: blasts or Jurkat cell lines [1-7]. These cells undergo activation-induced cell death (AICD) upon secondary activation, and the ROS produced are involved in apoptosis regulation and execution. Contrary to these studies, we have not observed any superoxide production in T-cell blasts or Jurkat T cells. This discrepancy may be explained by different methods used to measure 


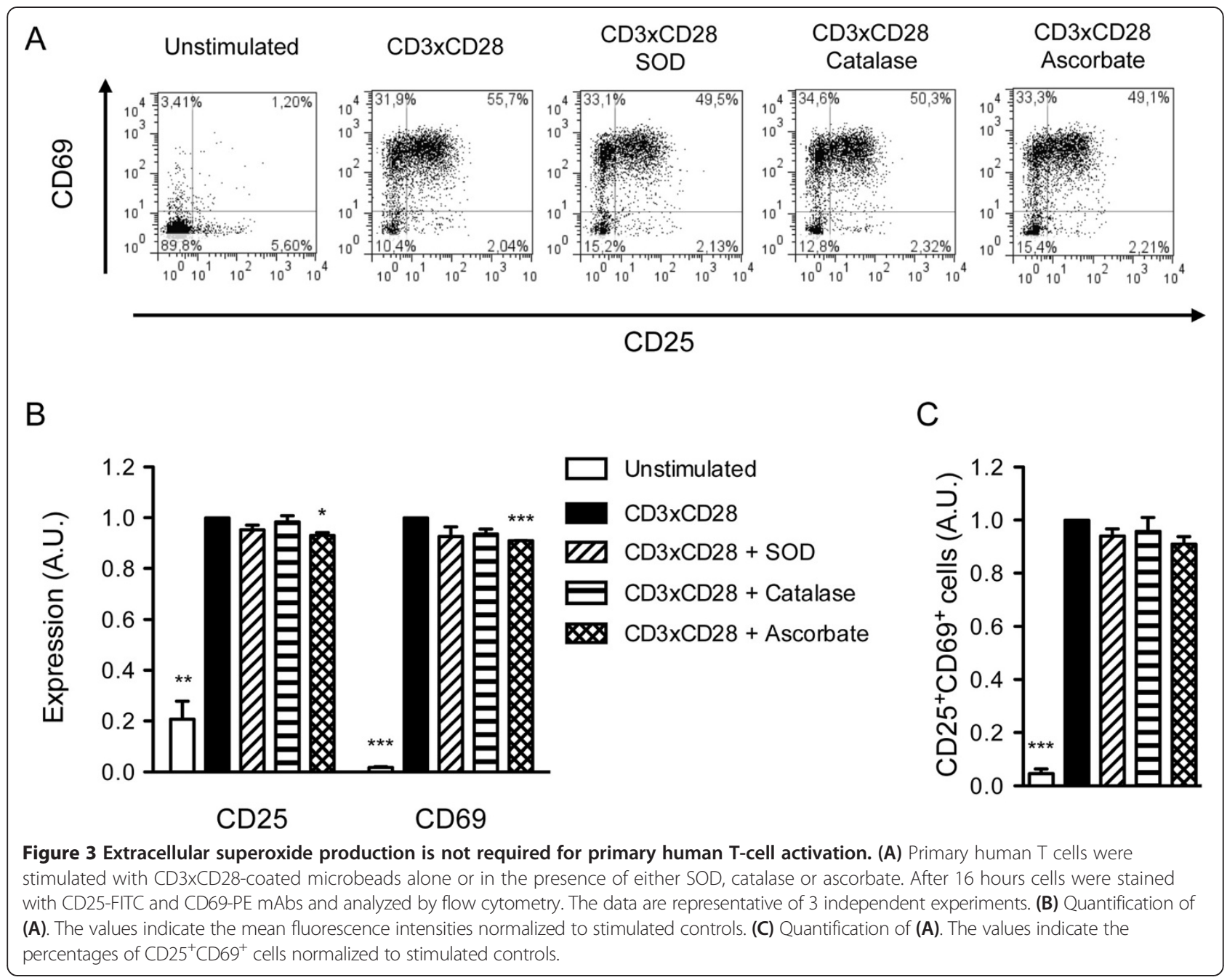

ROS production. In our experiments, we used luminolbased assay for detection of extracellular superoxide, whereas in aforementioned studies, DHE (for intracellular superoxide) or DCFDA (for intracellular $\mathrm{H}_{2} \mathrm{O}_{2}$ ) dyes were used. Moreover, in our study, we employed a system that closely mimics physiological stimulation of $\mathrm{T}$ cells by antigen-presenting cells (APCs) [25]. We used anti-CD3 and anti-CD28 mAbs immobilized on microbeads which provide focal stimulation. This cannot be obtained by other systems, including classical stimulation with soluble antibodies, which have been used in other studies. We have shown that, in contrast to soluble stimulation, which results in T-cell unresponsiveness, focal stimulation leads to T-cell activation, proliferation and cytokine production and hence mimics the effects of APCs. Finally, we performed our experiments on primary, non-preactivated cells, which underwent proliferation, not AICD, upon TCR stimulation.

Some reports have suggested that $\mathrm{T}$ cells do not produce ROS upon TCR stimulation, and that oxidation of the dyes observed in these studies is an artefact induced by ROS derived from contaminating phagocytic cells [9-12]. Those cells can be activated unspecifically by binding of stimulating antibodies to Fc receptors [26]. In our assay, we indeed detected a strong production of superoxide upon addition of microbeads coated with isotype controls, which most likely originated from monocytes contaminating the preparation (Additional file 2: Figure S2). Nevertheless, there was a statistically significant increase in luminol oxidation in T cells stimulated with $\mathrm{CD} 3 \times \mathrm{CD} 28$ as compared to isotype, indicating an additional T-cell specific superoxide production. Therefore, for ROS measurements in primary $\mathrm{T}$ cells purified from blood or tissues, it is crucial to include isotype controls, to discriminate ROS production derived from phagocytic cells.

One of the well-described sources of superoxide is the phagocytic NADPH oxidase. Importantly, the key component of this complex, gp91 ${ }^{\text {phox }}$, has been shown to be expressed in $\mathrm{T}$ cells [3]. However, the same study showed that $g p 91^{\text {phox-/- }}$ T-cell blasts were still able to inducibly produce superoxide similarly to WT T cells 

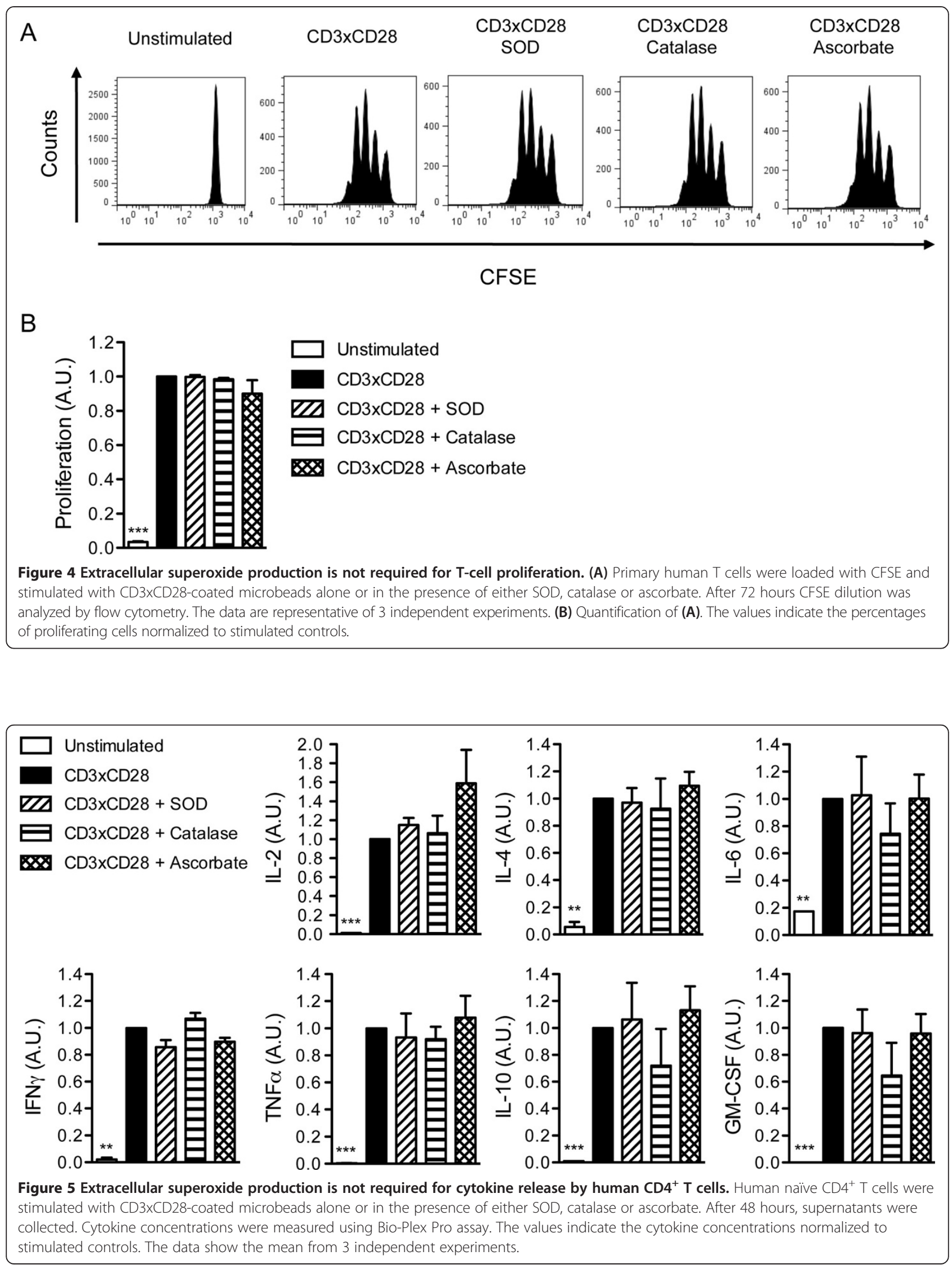


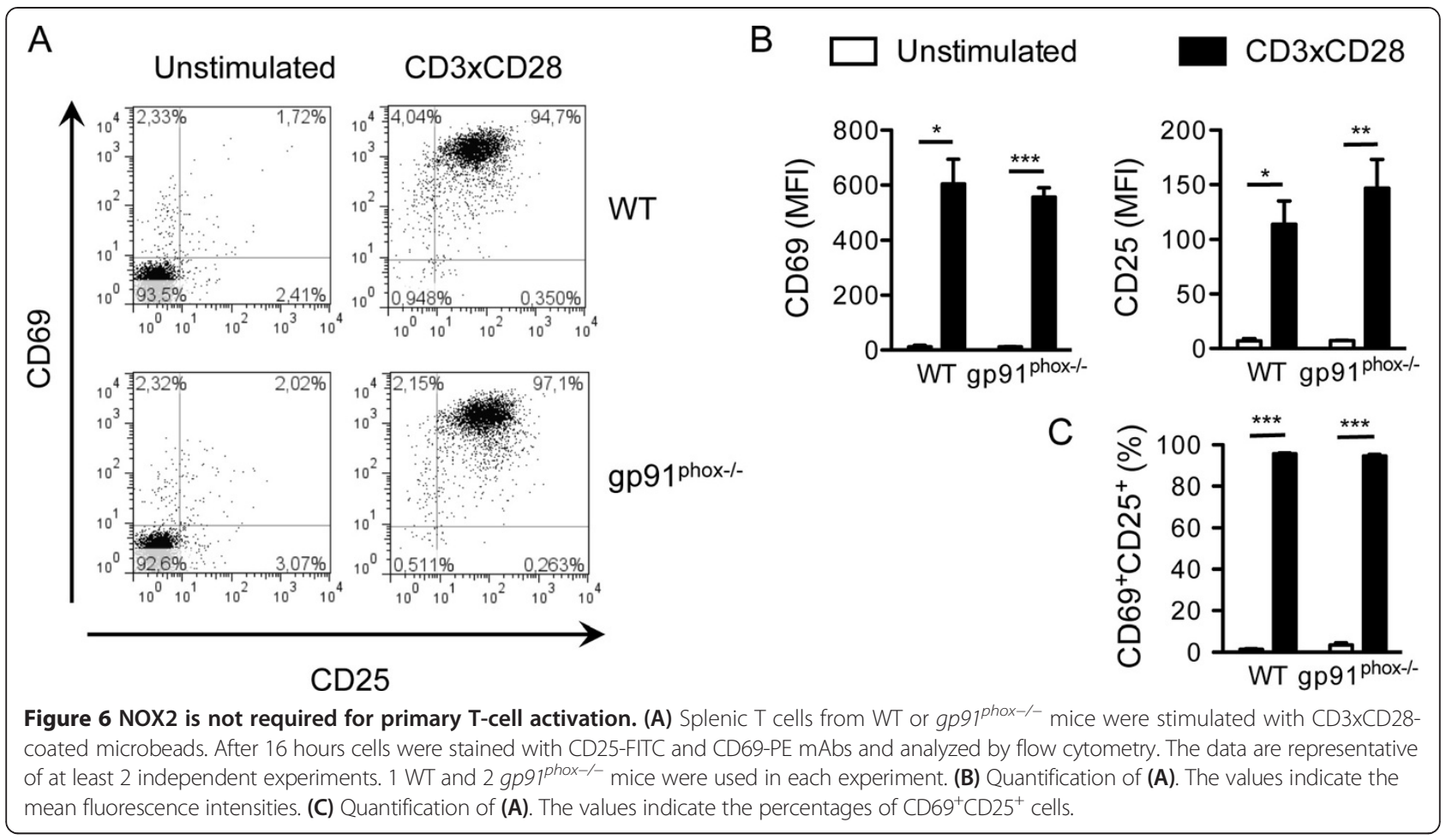

[3]. In contrary, we observed a complete absence of TCR-triggered superoxide production in primary $\mathrm{T}$ cells from $g p 91^{\text {phox-/- }}$ mice. The reason for this discrepancy might be the differences in cells, stimulation protocols and superoxide detection methods used. In the aforementioned study, T-cell blasts, stimulated with soluble antibodies, were most likely undergoing AICD, and superoxide from apoptotic mitochondria was detected by intracellular DHE dye. In our study, primary $\mathrm{T}$ cells were physiologically stimulated by immobilized antibodies and subsequently have activated NOX2 at the plasma membrane (in case of WT mice) or failed to do so (in case of $g p 91^{\text {phox-l- }}$ mice).

In addition to NOX2, other sources of ROS exist in T cells. Mitochondria represent one of those, and have been shown to be involved in AICD of human T-cell blasts [5,7] and antigen-specific expansion of murine $\mathrm{T}$ cells [8]. Additionally, it has been shown that mitochondria translocate to the immunological synapse [27], potentially creating a highly oxidizing environment. Although in

\section{A}

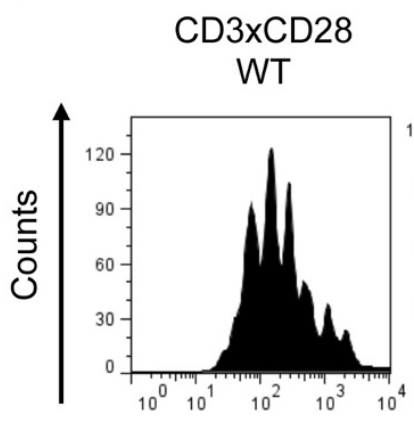

$\mathrm{CD} 3 \times \mathrm{CD} 28$ gp91 $1^{\text {phox-l- }}$

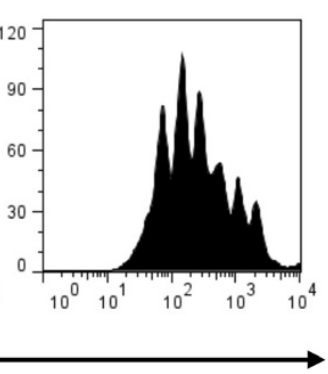

CFSE
B
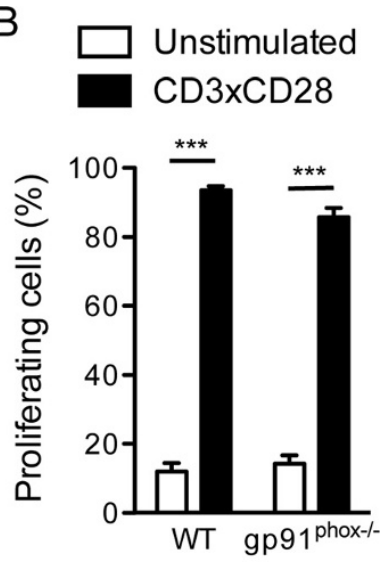

Figure 7 NOX2 is not required for T-cell proliferation. (A) Splenic T cells from WT or gp9 $1^{\text {phox-1- }}$ mice were loaded with CFSE and stimulated with CD3xCD28-coated microbeads. After 72 hours CFSE dilution was analyzed by flow cytometry. The data are representative of 2 independent experiments. 2 WT and 4 gp $91^{\text {phox }-1-}$ mice were used in each experiment. (B) Quantification of (A). The values indicate the percentages of proliferating cells. 
our system no superoxide was detected in the absence of NOX2, it is still possible that superoxide is produced in mitochondria upon TCR stimulation, because the Diogenes assay that we used most likely detects only extracellular superoxide. Moreover, mitochondria could produce superoxide at later stages of T-cell activation, whereas we focused on early events following TCR crosslinking. Despite the widespread idea that, upon activation, $\mathrm{T}$ cells switch from mitochondrial respiration to aerobic glycolysis [28], it has been shown recently that mitochondria are still the main source of energy and metabolites in activated $\mathrm{T}$ cells $[8,29]$. Therefore, results obtained from mitochondria-targeted sensors and inhibitors should be interpreted with great caution, as any interference with mitochondrial function is likely to cause severe alterations in cell metabolism or even trigger apoptosis.

To our surprise, T-cell activation and proliferation were not defective in primary $\mathrm{T}$ cells from $g p 91^{\text {phox-/- }}$ mice. We first thought that the effect could be obscured because of the high activation levels, so we repeated the experiments with low antibody concentration (Additional file 3: Figure S3). However, T cells from $g p 91^{\text {phox-/- }}$ mice displayed even slightly higher activation, than WT T cells. This observation could be in line with other studies which, by using mouse models with affected NADPH oxidase function (e.g. $g p 91^{\text {phox }}$ and $p 47^{\text {phox }}$ knock-out mice), showed an increased severity of T-cell mediated immune diseases, such as arthritis and experimental autoimmune encephalomyelitis [30-32]. However, the exact mechanisms responsible for this effect are not clear. Moreover, these mice have a defect in ROS production by phagocytic cells as well, which could have contributed to the development of these autoimmune diseases. In addition, it has been shown that $\mathrm{CD} 4^{+} \mathrm{T}$-cell blasts from $g p 91^{\text {phox-/- }}$ mice display skewing of cytokine profile towards Th1 [3].

In agreement with our results from $g p 91^{\text {phox-/- }}$ mice, natural antioxidants did not affect primary human T-cell activation and proliferation. This appears to be in contrast with some previously published data showing that antioxidants inhibit T-cell proliferation and IL-2 production [21]. However, non-naturally occurring antioxidant compounds were used in that study. Those are likely to induce various off-target effects. Interestingly, one study showed that concentrations of ascorbate required to inhibit proliferation or IL-2 production in T cells are two orders of magnitude higher than those required to inhibit ROS production [11].

Despite the fact that superoxide is produced upon TCR stimulation, it appears to be dispensable for T-cell activation, proliferation and cytokine production. This raises the question: why do $\mathrm{T}$ cells need to produce superoxide? An intriguing possibility is that extracellularly released superoxide serves as a feedback messenger to antigen-presenting cell, to signal successful activation.
Indeed, a tightly regulated crosstalk between dendritic cells and T cells has been demonstrated [24,33]. Further studies investigating $\mathrm{T}$ cell-APC interactions in vitro or in vivo are required to assess this hypothesis.

\section{Conclusions}

In summary, we showed that triggering of the T-cell receptor on primary human and mouse $\mathrm{T}$ cells induces rapid extracellular superoxide production, potentially via NADPH oxidase 2. Nevertheless, the functional importance of this event remains elusive, as we have not found any significant defects in the expression of activation markers, proliferation and cytokine secretion when superoxide production was abolished.

\section{Methods}

\section{Ethics}

Approval for these studies was obtained from the Ethics Committee of the Medical Faculty at the Otto-vonGuericke University, Magdeburg, Germany, with the permission number [107/09]. Informed consent was obtained in writing in accordance with the Declaration of Helsinki. All experiments involving mice were performed according to the guidelines of the State of Sachsen-Anhalt, Germany.

\section{Human T-cell purification and culture}

Peripheral blood mononuclear cells were isolated by Ficoll gradient (Biochrom AG) centrifugation of heparinized blood collected from healthy volunteers. $T$ cells were further purified by non-T cell depletion using human pan T-cell isolation kit and AutoMACS (all from Miltenyi Biotec). Purity of $\mathrm{T}$ cells, determined by flow cytometry, was routinely more than $96 \%$. T cells were cultured at $10^{6}$ cells $/ \mathrm{ml}, 37^{\circ} \mathrm{C}$ and $5 \% \mathrm{CO}_{2}$ in $\mathrm{RPMI}$ 1640 medium supplemented with stable glutamine (Biochrom AG), $10 \%$ fetal calf serum (PAN Biotech) and $2 \mu \mathrm{g} / \mathrm{ml}$ ciprobay (Bayer).

\section{Mouse T-cell purification and culture}

$g p 91^{\text {phox-/- }}$ mice were a kind gift from Dr. Katrin Breitbach (Friedrich Loeffler Institute of Medical Microbiology, Ernst-Moritz-Arndt University, Greifswald). Wild type control $\mathrm{C} 57 \mathrm{BL} / 6)^{\mathrm{Bom}}$ mice were obtained from Taconics. Mice were kept in pathogen-free conditions (SPF). Spleens from mice were passed through a fine mesh filter (BD Falcon) to obtain a single-cell suspension. $\mathrm{T}$ cells were purified by non-T cell depletion using mouse pan T-cell isolation kit and AutoMACS (all from Miltenyi Biotec). Purity of T cells, determined by flow cytometry, was routinely more than $96 \%$. The cells were cultured at $10^{6}$ cells/ $\mathrm{ml}, 37^{\circ} \mathrm{C}$ and $5 \% \mathrm{CO}_{2}$ in RPMI 1640 medium supplemented with stable glutamine (Biochrom AG), 10\% fetal 
calf serum PAN Biotech), $2 \mu \mathrm{g} / \mathrm{ml}$ ciprobay (Bayer) and $50 \mu \mathrm{M} \beta$-mercaptoethanol (Sigma Aldrich).

\section{T-cell stimulation}

$\mathrm{T}$ cells were stimulated with immobilized $\mathrm{CD} 3 \times \mathrm{CD} 28$ mAbs as previously described [25]. Briefly, SuperAvidin ${ }^{\text {tix }}$ coated polystyrene microspheres (Bangs laboratories, Inc., $\varnothing \sim 10 \mu \mathrm{m}$, binding capacity: 0,02-0,04 $\mu \mathrm{g}$ biotin/mg) were coated with biotinylated CD3 (clone UCHT1) and CD28 (clone CD28.2) mAbs (10 $\mu \mathrm{g} / \mathrm{ml}$ each, BioLegend) for $30 \mathrm{~min}$ at $37^{\circ} \mathrm{C}$ in PBS Dulbecco (Biochrom AG). Antibody-coated microspheres were washed three times, resuspended in PBS at $10^{8}$ beads $/ \mathrm{ml}$ and incubated with T cells in a 1 bead per cell ratio. Microspheres coated with $20 \mu \mathrm{g} / \mathrm{ml}$ of biotinylated mouse IgG1א (eBioscience) were used as a control.

Stimulations in the presence of $100 \mathrm{U} / \mathrm{ml}$ superoxide dismutase from bovine erythrocytes, $1000 \mathrm{U} / \mathrm{ml}$ catalase from Corynebacterium glutamicum and $100 \mu \mathrm{M}$ L-ascorbic acid (all from Sigma-Aldrich) were performed by pre-incubating $\mathrm{T}$ cells for $30 \mathrm{~min}$ with the compounds before stimulation.

Mouse T cells were stimulated with CD3 (clone 1452C11) and CD28 (clone 37.51) mAbs $(10 \mu \mathrm{g} / \mathrm{ml}$ each, both from BD Pharmingen) immobilized on microspheres as described above. Microspheres coated with

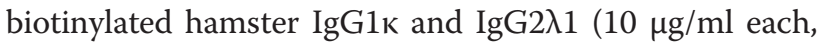
both from BD Pharmingen) were used as a control.

\section{Superoxide production assay}

For superoxide detection the Diogenes Cellular Luminescence Enhancement System (National Diagnostics) was used according to the manufacturer's instructions. Briefly, $\mathrm{T}$ cells were centrifuged, resuspended at the density of $10^{7}$ cells $/ \mathrm{ml}$ in a prewarmed serum-free phenol red-free RPMI 1640 medium (Gibco) and aliquoted to black polystyrene flat bottom 96-well plate (Costar, Corning Inc., $100 \mu \mathrm{l}$ suspension per well). Diogenes Reagent and Diogenes Activator were freshly mixed in a 1:9 ratio and aliquoted to the same plate $(50 \mu \mathrm{l}$ per well). Cells were then stimulated as described above and luminescence was repeatedly measured with 5 min intervals for the total of 60 min using TriStar LB941 multimode reader (Berthold technologies), keeping cells at $37^{\circ} \mathrm{C}$.

\section{Activation assay}

$\mathrm{T}$ cells were seeded onto flat bottom polystyrene 48-well plates (Costar, Corning Inc.) at $10^{6}$ cells $/ \mathrm{ml}$ in a volume of $500 \mu \mathrm{l}$ per well and stimulated as described above. After $16 \mathrm{~h}$, cells were stained with FITC- or PE-labeled mAbs against CD25 and CD69 (BD Pharmingen, BioLegend) and analyzed by flow cytometry using a FACSCalibur and CellQuest software or BD LSRFortessa and FACSDiva
Software 6.1.3 (all from BD Biosciences), and FlowJo 7.5.5 (Tree Star, Inc.).

\section{Proliferation assay}

$T$ cells were centrifuged, resuspended in $1 \mathrm{ml}$ of PBS Dulbecco (Biochrom AG) and labeled with 2,5 $\mu \mathrm{M}$ CFSE (Invitrogen) for $15 \mathrm{~min}$ at $37^{\circ} \mathrm{C}$. Then cells were washed twice, resuspended in medium at the density of $10^{6}$ cells $/ \mathrm{ml}$, seeded onto flat bottom polystyrene 48-well plates (Costar, Corning Inc.) in a volume of $500 \mu \mathrm{l} /$ well and stimulated as described above. Cells were then cultured for $72 \mathrm{~h}$ and proliferation was assessed by CFSE dilution using FACSCalibur and CellQuest software or BD LSRFortessa and FACSDiva Software 6.1.3 (all from BD Biosciences), and FlowJo 7.5.5 (Tree Star, Inc.).

\section{Cytokine assay}

Human naïve $\mathrm{CD} 4^{+} \mathrm{T}$ cells were purified from peripheral blood mononuclear cells by non-T cell depletion using human naïve $\mathrm{CD} 4^{+} \mathrm{T}$-cell isolation kit and AutoMACS (all from Miltenyi Biotec). T cells were resuspended in serum-free X-VIVO 15 medium supplemented with gentamycin (Lonza), seeded onto flat bottom polystyrene 48-well plates (Costar, Corning Inc.) at $10^{6}$ cells $/ \mathrm{ml}$ in a volume of $1 \mathrm{ml}$ per well and stimulated as described above. After $48 \mathrm{~h}$ supernatants were harvested, supplemented with 0,5\% bovine serum albumin (Sigma-Aldrich) and frozen. Later, cytokine concentrations in the supernatants were measured using Bio-Plex Pro assay on the BioPlex 200 system (all from Bio-Rad) according to the manufacturer's protocol.

\section{Statistics}

Statistical analysis was performed using GraphPad Prism 5 (GraphPad Software, Inc.). $P$ values were determined by two-tailed Student's $t$ test. ${ }^{*} \mathrm{P}<0.05,{ }^{* * *} \mathrm{P}<0.01$, ${ }^{* * * *} \mathrm{P}<0.001$.

\section{Additional files}

Additional file 1: Figure S1. Extracellular superoxide production is not required for cytokine release by human $\mathrm{CD}^{+} \mathrm{T}$ cells. Human naïve $\mathrm{CD} 4^{+}$ T cells were stimulated with CD3XCD28-coated microbeads alone or in the presence of either SOD, catalase or ascorbate. After 48 hours, supernatants were collected. Cytokine concentrations were measured using Bio-Plex Pro assay. The values indicate the absolute cytokine concentrations.The data show the mean from 3 independent experiments.

Additional file 2: Figure S2. TCR stimulation induces extracellular superoxide release in primary human and mouse T cells. (A and B) T cells were stimulated with CD3xCD28- or isotype-coated microbeads. Superoxide production was measured with Diogenes assay at 5 min intervals. The values indicate the increase in luminescence in CD3xCD28- or isotype-stimulated samples relative to unstimulated samples. (A) Primary human $T$ cells were used. The data show the mean from 16 independent experiments. (B) Splenic $\mathrm{T}$ cells from either WT or $g p 91^{\text {phox- }-}$ mice were used. The data show the mean from 3 independent experiments. 2 WT and 4 gp9 $1^{\text {phox }-1-}$ mice were used in each experiment. 
Additional file 3: Figure S3. NOX2 is not required for primary T-cell activation. Splenic T cells from WT or $g p 91^{\text {phox- } /-}$ mice were stimulated with CD3 antibody, immobilized on culture plates in concentrations 5 $\mu \mathrm{g} / \mathrm{ml}$ or $0,15 \mu \mathrm{g} / \mathrm{ml}$. After 16 hours, cells were stained with CD25-FITC and CD69-PE mAbs and analyzed by flow cytometry. The data are representative of 2 independent experiments. The values indicate the mean fluorescence intensities or the percentages of $\mathrm{CD} 69^{+} \mathrm{CD} 25^{+}$cells.

\section{Abbreviations}

AICD: Activation-induced cell death; APC: Antigen-presenting cell; CFSE: Carboxyfluorescein succinimidyl ester; DCFDA: 2',7'-dichlorofluorescin diacetate; DHE: dihydroethydium; FITC: Fluorescein isothiocyanate; NOX2: NADPH oxidase 2; PE: Phycoerythrin; ROS: Reactive oxygen species; SOD: Superoxide dismutase; TCR: T-cell receptor; WT: Wild type.

\section{Competing interests}

The authors declare that they have no competing interests.

\section{Authors' contributions}

AVB participated in the design of the study, carried out all the experiments, performed the statistical analysis and drafted the manuscript. BS participated in the design of the study and helped to draft the manuscript. LS conceived of and coordinated the study and helped to draft the manuscript. All authors read and approved the final manuscript.

\section{Acknowledgements}

We are grateful to Dr. Katrin Breitbach for kindly providing gp $91^{\text {phox }} \mathrm{KO}$ mice, Dr. Jonathan A Lindquist and Clemens Camman for helping with cytokine determination and to Ines Meinert for excellent technical assistance. The work was supported by grants from the German Research Foundation (DFG) to LS and BS (FOR-521, SFB854, and SPP1710). AVB was additionally supported by stipend from Otto-von-Guericke University, Magdeburg, Germany.

\section{Author details}

'Institute of Molecular and Clinical Immunology, Medical Faculty, Otto-von-Guericke University, Leipziger Str. 44, 39120 Magdeburg, Germany. ${ }^{2}$ Department of Immune Control, Helmholtz Centre for Infection Research, Inhoffenstrasse 7, 38124 Braunschweig, Germany.

Received: 10 February 2014 Accepted: 21 July 2014

Published: 1 August 2014

\section{References}

1. Devadas S, Zaritskaya L, Rhee SG, Oberley L, Williams MS: Discrete generation of superoxide and hydrogen peroxide by $\mathrm{T}$ cell receptor stimulation: selective regulation of mitogen-activated protein kinase activation and fas ligand expression. J Exp Med 2002, 195:59-70.

2. Kwon J, Devadas S, Williams MS: T cell receptor-stimulated generation of hydrogen peroxide inhibits MEK-ERK activation and Ick serine phosphorylation. Free Radic Biol Med 2003, 35:406-417.

3. Jackson SH, Devadas S, Kwon J, Pinto LA, Williams MS: T cells express a phagocyte-type NADPH oxidase that is activated after T cell receptor stimulation. Nat Immunol 2004, 5:818-827.

4. Gulow K, Kaminski M, Darvas K, Suss D, Li-Weber M, Krammer PH: HIV-1 trans-activator of transcription substitutes for oxidative signaling in activation-induced T cell death. J Immunol 2005, 174:5249-5260.

5. Kaminski M, Kiessling M, Suss D, Krammer PH, Gulow K: Novel Role for Mitochondria: Protein Kinase C -Dependent Oxidative Signaling Organelles in Activation-Induced T-Cell Death. Mol Cell Biol 2007, 27:3625-3639.

6. Kwon J, Shatynski KE, Chen H, Morand S, de Deken X, Miot F, Leto TL, Williams MS: The nonphagocytic NADPH oxidase Duox1 mediates a positive feedback loop during T cell receptor signaling. Sci Signal 2010, 3:ra59.

7. Kaminski MM, Roth D, Sass S, Sauer SW, Krammer PH, Gulow K: Manganese superoxide dismutase: a regulator of $\mathrm{T}$ cell activation-induced oxidative signaling and cell death. Biochim Biophys Acta 1823, 2012:1041-1052.

8. Sena LA, Li S, Jairaman A, Prakriya M, Ezponda T, Hildeman DA, Wang CR, Schumacker PT, Licht JD, Perlman H, Bryce PG, Chandel NS: Mitochondria are required for antigen-specific $\mathrm{T}$ cell activation through reactive oxygen species signaling. Immunity 2013, 38:225-236.
9. Benichou G, Kanellopoulos JM, Mitenne F, Galanaud P, Leca G: T-cell chemiluminescence. A novel aspect of T-cell membrane activation studied with a Jurkat tumour cell line. Scand J Immunol 1989, 30:265-269.

10. Rabesandratana H, Fournier AM, Chateau MT, Serre A, Dornand J: Increased oxidative metabolism in PMA-activated lymphocytes: a flow cytometric study. Int I Immunopharmacol 1992, 14:895-902.

11. Tatla S, Woodhead V, Foreman JC, Chain BM: The role of reactive oxygen species in triggering proliferation and IL-2 secretion in T cells. Free Radic Biol Med 1999, 26:14-24.

12. van Reyk DM, King NJ, Dinauer MC, Hunt NH: The intracellular oxidation of 2',7'-dichlorofluorescin in murine T lymphocytes. Free Radic Biol Med 2001, 30:82-88.

13. Reth M: Hydrogen peroxide as second messenger in lymphocyte activation. Nat Immunol 2002, 3:1129-1134.

14. Denu JM, Tanner KG: Specific and reversible inactivation of protein tyrosine phosphatases by hydrogen peroxide: evidence for a sulfenic acid intermediate and implications for redox regulation. Biochemistry 1998, 37:5633-5642.

15. Haddad JJ: Antioxidant and prooxidant mechanisms in the regulation of redox(y)-sensitive transcription factors. Cell Signal 2002, 14:879-897.

16. Bogeski I, Kummerow C, Al-Ansary D, Schwarz EC, Koehler R, Kozai D, Takahashi N, Peinelt C, Griesemer D, Bozem M, Mori Y, Hoth M, Niemeyer BA: Differential redox regulation of ORAI ion channels: a mechanism to tune cellular calcium signaling. Sci Signal 2010, 3:ra24.

17. Gringhuis SI, der Voort EA P-V, Leow A, Nivine Levarht EW, Breedveld FC, Verweij CL: Effect of redox balance alterations on cellular localization of LAT and downstream T-cell receptor signaling pathways. Mol Cell Biol 2002, 22:400-411.

18. Rogers KR, Morris CJ, Blake DR: Oxidation of thiol in the vimentin cytoskeleton. Biochem J 1991, 275(Pt 3):789-791.

19. Lambeth JD: NOX enzymes and the biology of reactive oxygen. Nat Rev Immunol 2004, 4:181-189.

20. Bedard K, Krause KH: The NOX family of ROS-generating NADPH oxidases: physiology and pathophysiology. Physiol Rev 2007, 87:245-313.

21. Dornand J, Gerber M: Inhibition of murine T-cell responses by antioxidants: the targets of lipo-oxygenase pathway inhibitors. Immunology 1989, 68:384-391.

22. Staal FJ, Anderson MT, Staal GE, Herzenberg LA, Gitler C: Redox regulation of signal transduction: tyrosine phosphorylation and calcium influx. Proc Natl Acad Sci U S A 1994, 91:3619-3622.

23. Suthanthiran M, Anderson ME, Sharma VK, Meister A: Glutathione regulates activation-dependent DNA synthesis in highly purified normal human T lymphocytes stimulated via the CD2 and CD3 antigens. Proc Natl Acad Sci U S A 1990, 87:3343-3347.

24. Angelini G, Gardella S, Ardy M, Ciriolo MR, Filomeni G, Di Trapani G, Clarke F Sitia R, Rubartelli A: Antigen-presenting dendritic cells provide the reducing extracellular microenvironment required for T lymphocyte activation. Proc Natl Acad Sci U S A 2002, 99:1491-1496.

25. Arndt B, Poltorak M, Kowtharapu BS, Reichardt P, Philipsen L, Lindquist JA Schraven B, Simeoni L: Analysis of TCR activation kinetics in primary human T cells upon focal or soluble stimulation. J Immunol Methods 2013, 387:276-283.

26. Pricop L, Gokhale J, Redecha P, Ng SC, Salmon JE: Reactive oxygen intermediates enhance Fc gamma receptor signaling and amplify phagocytic capacity. J Immunol 1999, 162:7041-7048.

27. Contento RL, Campello S, Trovato AE, Magrini E, Anselmi F, Viola A: Adhesion shapes T cells for prompt and sustained T-cell receptor signalling. EMBO J 2010, 29:4035-4047.

28. Jones $R G$, Thompson $C B$ : Revving the engine: signal transduction fuels T cell activation. Immunity 2007, 27:173-178.

29. Chang $\mathrm{CH}$, Curtis JD, Maggi LB Jr, Faubert B, Villarino AV, O'Sullivan D, Huang SC, van der Windt GJ, Blagih J, Qiu J, Weber JD, Pearce EJ, Jones RG, Pearce EL: Posttranscriptional control of T cell effector function by aerobic glycolysis. Cell 2013, 153:1239-1251.

30. Hultqvist M, Olofsson P, Holmberg J, Backstrom BT, Tordsson J, Holmdahl R: Enhanced autoimmunity, arthritis, and encephalomyelitis in mice with a reduced oxidative burst due to a mutation in the Ncf1 gene. Proc Natl Acad Sci U S A 2004, 101:12646-12651.

31. Gelderman KA, Hultavist M, Pizzolla A, Zhao M, Nandakumar KS, Mattsson R, Holmdahl R: Macrophages suppress T cell responses and arthritis development in mice by producing reactive oxygen species. J Clin Invest 2007, 117:3020-3028. 
32. Lee $\mathrm{K}$, Won HY, Bae MA, Hong JH, Hwang ES: Spontaneous and agingdependent development of arthritis in NADPH oxidase 2 deficiency through altered differentiation of $\mathrm{CD} 11 \mathrm{~b}+$ and Th/Treg cells. Proc Natl Acad Sci U S A 2011, 108:9548-9553.

33. Hivroz C, Chemin K, Tourret M, Bohineust A: Crosstalk between T lymphocytes and dendritic cells. Crit Rev Immunol 2012, 32:139-155.

doi:10.1186/s12964-014-0050-1

Cite this article as: Belikov et al:: TCR-triggered extracellular superoxide production is not required for T-cell activation. Cell Communication and Signaling 2014 12:50.

\section{Submit your next manuscript to BioMed Central and take full advantage of:}

- Convenient online submission

- Thorough peer review

- No space constraints or color figure charges

- Immediate publication on acceptance

- Inclusion in PubMed, CAS, Scopus and Google Scholar

- Research which is freely available for redistribution 